VAYEGO, S.A., DIONELLO, N.J.L. e FIGUEIREDO, E.A.P. Estimativas de parâmetros genéticos e tendências genéticas para algumas características de importância econômica em linhagem materna de frango de corte sob seleção. PUBVET, Londrina, V. 5, N. 29, Ed. 176, Art. 1191, 2011.

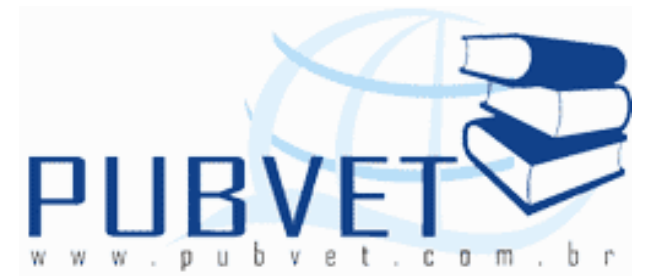

PUBVET, Publicações em Medicina Veterinária e Zootecnia.

\title{
Estimativas de parâmetros genéticos e tendências genéticas para algumas características de importância econômica em linhagem materna de frango de corte sob seleção
}

Stela Adami Vayego ${ }^{1}$, Nelson José Laurino Dionello², Elsio Antonio Pereira de Figueiredo ${ }^{3}$

${ }^{1}$ Departamento de Estatística/Universidade Federal do Paraná

${ }^{2}$ Departamento de Zootecnia/Universidade Federal de Pelotas ${ }^{3}$ EMBRAPA/ Suínos e Aves

\section{Resumo}

Estimativas dos parâmetros genéticos de características produtivas em linhagem materna de matrizes de frango de corte foram obtidas usando a metodologia de máxima verossimilhança restrita. Os dados analisados são provenientes do programa de melhoramento genético da EMBRAPA Suínos e Aves. Na linhagem materna (PP) foram avaliadas as características de peso corporal aos 42 dias de idade (P42), idade à maturidade sexual (IMS), produção de ovos às 35 e 64 semanas de idade (PD35 e PD64). Os componentes de variância e covariância foram estimados através do programa DFREML, utilizando o algoritmo DFREML. As estimativas de herdabilidade obtidas foram moderadas variando de 0,21 a 0,37. As correlações genéticas foram: 0,24 entre P42 e IMS; -0,23 entre P42 e PD35; -0,28 entre P42 e PD64; -0,42 entre IMS e PD35; -0,16 entre IMS e PD64. O estudo da 
VAYEGO, S.A., DIONELLO, N.J.L. e FIGUEIREDO, E.A.P. Estimativas de parâmetros genéticos e tendências genéticas para algumas características de importância econômica em linhagem materna de frango de corte sob seleção. PUBVET, Londrina, V. 5, N. 29, Ed. 176, Art. 1191, 2011.

tendência genética das características indicou que progresso genético está sendo obtido.

Palavras-chave: modelos mistos, REML, matrizes de frango de corte, parâmetros genéticos, tendência genética

\section{Estimates of genetic parameters and trends of productive traits in broiler breeder lines under selection}

\section{Abstract}

Estimates of genetic parameters of productive traits in broiler breeder lines were obtained through mixed models methodology. The data analyzed came from the breeding program of EMBRAPA Suínos e Aves. In the sire line (TT): body weight at 42 days of age (P42), age at maturity sexual (IMS) and eggs production at 35 and 64 week of age (P35 and PD64). Estimates of variances and covariances were obtained using the software DFREML, which employs the algorithms DFREML. The herdability estimates obtained were moderate, in the range of 0,21 to 0,37 . The genetics correlations were: 0,24 between P42 and IMS; $-0,23$ between P42 and PD35; and $-0,28$ between P42 and PD64; $-0,42$ between IMS and PD35; -0,16 between IMS and PD64.. The study of the genetic trend of the traits indicated that genetic progress has been obtained.

Keywords: mixed models, REML, broilers breeder, genetic parameters, genetic trend

\section{Introdução}

O predomínio de grandes empresas no mercado de genética avícola se deve às tecnologias empregadas na produção de linhagens, que trazem em seu perfil características que atendem às necessidades do mercado e da indústria. Linhagens adequadas ao nível tecnológico da cadeia, técnicas de manejo e gostos do consumidor têm sido desenvolvidas. Segundo estudo realizado pela CNPSA/EMBRAPA em 2001 a participação da variável material genético representa, aproximadamente, $8,3 \%$ do custo total da avicultura de corte. 
VAYEGO, S.A., DIONELLO, N.J.L. e FIGUEIREDO, E.A.P. Estimativas de parâmetros genéticos e tendências genéticas para algumas características de importância econômica em linhagem materna de frango de corte sob seleção. PUBVET, Londrina, V. 5, N. 29, Ed. 176, Art. 1191, 2011.

A busca de genótipos mais produtivos e mais compatíveis com as condições ambientais prevalentes no país deve ser a preocupação dos programas de melhoramento animal. Para isso, é prioritário o estabelecimento de programas estáveis de ação, amparados com suportes financeiros adequados. A diversidade de material genético, existente no Brasil facilita o trabalho de melhoramento, entretanto, a reprodução indiscriminada desse material sem um esquema de seleção adequado sofre com problemas resultantes da depressão por endogamia (MARTINS, 2002). Portanto, é necessário intensificar processos de identificação dos genótipos superiores e multiplicação dos mesmos, através de programas coordenados de melhoramento animal (PEREIRA, 1996).

Desde 1983, a EMBRAPA desenvolve um programa de melhoramento completo (linhas puras, bisavozeiros, avozeiros e matrizeiros) para produtos de corte e postura, e mantém o programa voltado a pequenos e médios produtores, e cooperativas, utilizando-se de técnicas de genética quantitativa. De acordo com FIGUEIREDO (2005) a utilização de uma ou duas linhas paternas e duas linhas maternas foram importantes por permitir melhorar características antagônicas, como por exemplo, produção de ovos e peso corporal à maturidade sexual.

Os trabalhos de melhoramento genético trouxeram impactos expressivos na dinâmica da produção por meio de aperfeiçoamento de características como ganho de peso, conversão alimentar e rendimento da carcaça. O melhoramento genético em aves permitiu a criação de linhagens altamente eficientes na conversão alimentar. Em países lideres do setor, nos anos 70, já se verificava uma taxa de conversão alimentar de $2 \mathrm{Kg}$ de ração para cada $\mathrm{Kg}$ de peso vivo e idade ao abate de 49 dias.

Algumas respostas correlacionadas à seleção para alta taxa de crescimento, como deposição excessiva de gordura, problemas de fraqueza de pernas e ascite, que é uma demonstração de que o sistema circulatório da ave nem sempre suporta a grande massa corporal que possui, tornou-se uma realidade. 
VAYEGO, S.A., DIONELLO, N.J.L. e FIGUEIREDO, E.A.P. Estimativas de parâmetros genéticos e tendências genéticas para algumas características de importância econômica em linhagem materna de frango de corte sob seleção. PUBVET, Londrina, V. 5, N. 29, Ed. 176, Art. 1191, 2011.

Para o programa de melhoramento genético animal funcionar é necessário que o objetivo e o critério de seleção estejam bem definidos. Para uma correta definição do critério de seleção são necessárias informações confiáveis a respeito dos parâmetros genéticos (herdabilidades e correlações genéticas) e fenotípicos (correlações fenotípicas) associadas às características envolvidas no melhoramento.

Para estimar os parâmetros genéticos e fenotípico é necessário que se tenha conhecimento das magnitudes das variâncias genéticas aditivas e fenotípicas da característica avaliada ou de sua herdabilidade (CARNEIRO et al., 2004). Essas variâncias geralmente são desconhecidas tornando necessário, primeiro, estimar componentes de (co)variâncias e depois estimar os parâmetros genéticos e fenotípicos (KENNEDY, 1981).

O uso dos métodos de máxima verossimilhança para estimar os componentes de (co)variâncias tem sido estimulado, em análises de dados de reprodução animal através do Modelo Animal (AM), pois são consideravelmente menos viesados pela seleção que seus correspondentes de ANOVA (MEYER \& THOMPSON, 1984). De maneira geral, estudos teóricos indicam que inferências pontuais realizadas a partir de funções de verossimilhança não são afetadas por algumas formas de seleção (RESENDE \& ROSA-PEREZ, 2001). Isto fez com que o método REML se tornasse padrão para a estimação de componentes de variância em programas de melhoramento genético.

Este estudo foi realizado com o objetivo estimar os componentes de (co)variâncias, parâmetros genéticos (herdabilidades e correlações) e as tendências genéticas para algumas características de importância econômica em linhagem materna de frango de corte.

\section{Material e Métodos}

O estudo foi desenvolvido utilizando-se informações de parentesco de 32167 matrizes fêmea de frangos de corte, referente ao período de 1995 a 2003, produzindo 8 gerações, do Banco Ativo de Germoplasma para Aves da EMBRAPA Suínos e Aves em Concórdia, Santa Catarina. 
VAYEGO, S.A., DIONELLO, N.J.L. e FIGUEIREDO, E.A.P. Estimativas de parâmetros genéticos e tendências genéticas para algumas características de importância econômica em linhagem materna de frango de corte sob seleção. PUBVET, Londrina, V. 5, N. 29, Ed. 176, Art. 1191, 2011.

Este banco tem como objetivo manter sob seleção as linhagens puras de frango de corte que dão origem aos produtos EMBRAPA 021 e EMBRAPA 041 e mais as linhagens de controle de interesse para pesquisa em genética e melhoramento de aves. Na seleção da linhagem materna, são valorizadas características de viabilidade geral e específica, fertilidade, eclodibilidade, produção de ovos incubáveis, empenamento e ausência de defeitos.

No presente trabalho foram avaliadas as características peso corporal aos 42 dias de idade (P42), idade à maturidade sexual (IMS), produção de ovos às 35 semanas de idade (PD35) e produção de ovos às 64 semanas de idade (PD64). As informações referiam-se a 1962 aves.

Os componentes de variância e covariância foram estimados utilizando-se o programa DFREML (Derivative-Free resticted Maximum Likelihood - versão 3.0), desenvolvido por MEYER (1988), que emprega o AM-BLUP, através do pacote DXMUX..

Utilizou-se o seguinte modelo misto, em sua forma matricial:

$$
\underset{\sim}{\mathrm{y}}=\underset{\sim}{\mathrm{X}}+\underset{\sim}{\mathrm{Zu}}+\underset{\sim}{\mathrm{e}}
$$

onde $\underset{\sim}{y}$ é o vetor (nqx1) de observações de q características medidas organizadas dentro cada animal, sendo n o número de animais em avaliação; ${ }_{\sim}^{\beta}$ : é o vetor (pqx1) de efeitos fixos, com $\mathrm{p}$ o número de efeitos fixos; $\mathrm{X}$ : é a matriz (nqxpq) de incidência de p efeitos fixos; $\underset{\sim}{u}$ : é o vetor (nqx1) de efeitos aleatórios (efeitos genéticos aditivos dos animais); Z: é uma matriz diagonal (nqxnq) de incidência de efeitos aleatórios, constituída de "1" ou " 0 ", na diagonal principal, dependendo se a característica foi medida ou não, no animal e $\underset{\sim}{\mathrm{e}}$ : é o vetor (nqx1) de variáveis aleatórias não observáveis, dito vetor de erros aleatórios.

As pressuposições da distribuição multivariada de ${ }_{\sim}^{\mathrm{y}} \underset{\sim}{\mathrm{u}} \mathrm{e} \underset{\sim}{\mathrm{e}}$ são: 
VAYEGO, S.A., DIONELLO, N.J.L. e FIGUEIREDO, E.A.P. Estimativas de parâmetros genéticos e tendências genéticas para algumas características de importância econômica em linhagem materna de frango de corte sob seleção. PUBVET, Londrina, V. 5, N. 29, Ed. 176, Art. 1191, 2011.

$$
\left[\begin{array}{c}
\mathrm{y} \\
\tilde{u} \\
\tilde{\mathrm{e}} \\
\sim
\end{array}\right] \sim \mathrm{N}\left\{\left[\begin{array}{c}
\mathrm{X} \beta \\
\tilde{0} \\
\tilde{\tilde{0}} \\
\sim
\end{array}\right] ;\left[\begin{array}{ccc}
Z G Z^{\prime}+\mathrm{R} & \mathrm{ZG} & \mathrm{R} \\
\mathrm{GZ} & \mathrm{G} & \phi \\
\mathrm{R} & \phi & \mathrm{R}
\end{array}\right]\right\} .
$$

Estando as medidas ordenadas dentro de cada animal no vetor $\underset{\sim}{\mathrm{y}}$, as matrizes G e R são definidas por:

$$
G=A \square G_{O} \quad \text { e } R=I \square R_{0}
$$

onde $\otimes$ denota produto de Kronecker; A é a matriz ( $\mathrm{nxn}$ ) de parentesco; I é a matriz identidade ( $n \times n) ; G_{0}$ é a matriz (qxq) de variância e covariância genética aditiva entre as $\mathrm{q}$ características, definida por:

$$
G_{0}=\left[\begin{array}{cccc}
\sigma_{A_{1}}^{2} & \sigma_{A_{1} A_{2}} & \square & \sigma_{A_{1} A_{q}} \\
\sigma_{A_{2} A_{1}} & \sigma_{A 2}^{2} & \square & \sigma_{A_{2} A_{q}} \\
\square & \square & \square & \\
\sigma_{A_{1} A_{q}} & \sigma_{A_{2} A_{q}} & \square & \sigma_{A_{q}}^{2}
\end{array}\right] \text {, em que } \sigma_{A_{i}}^{2} \text { é a variância genética aditiva da i- }
$$

ésima característica e ${ }^{\sigma_{A_{i}} A_{j}}$ é a covariância genética entre as característica i e $\mathrm{j}, \operatorname{com} \mathrm{i}=1,2, \ldots, \mathrm{q}$ e $\mathrm{j}=1,2, \ldots, \mathrm{q}$ e $\mathrm{R}_{0}$ é a matriz (qxq) de variância e covariância residual entre as $q$ características, definida por:

$$
R_{0}=\left[\begin{array}{cccc}
\sigma_{e_{1}}^{2} & \sigma_{e_{1} e_{2}} & \square & \sigma_{e_{1} e_{q}} \\
\sigma_{e_{2} e_{1}} & \sigma_{e 2}^{2} & \square & \sigma_{e_{2} e_{q}} \\
\square & \square & \square & \\
\sigma_{e_{1} e_{q}} & \sigma_{e_{2} e_{q}} & \square & \sigma_{e_{q}}^{2}
\end{array}\right] \text {, em que } \sigma_{e_{i}}^{2} \text { é a variância residual da i-ésima }
$$

característica e $\sigma_{e_{i} e_{j}}$ é a covariância residual entre as característica i e j, com i $=1,2, \ldots, q$ e $j=1,2, \ldots, q$.

O vetor de observações $\underset{\sim}{y}$, a matriz de incidência de efeitos fixos $X$, a matriz de incidência de valores genéticos $\mathrm{Z}$ e o vetor de valores genéticos $\mathrm{u}_{\sim}$ apresentam nq linhas mostrando cada observação individual, ou seja, que cada animal produz q equações. Assim, no modelo animal o número de equações a 
VAYEGO, S.A., DIONELLO, N.J.L. e FIGUEIREDO, E.A.P. Estimativas de parâmetros genéticos e tendências genéticas para algumas características de importância econômica em linhagem materna de frango de corte sob seleção. PUBVET, Londrina, V. 5, N. 29, Ed. 176, Art. 1191, 2011.

serem resolvidas equivale ao número de animais vezes o número de características (nq).

O sistema de equações do modelo misto é:

$$
\left[\begin{array}{cc}
X^{\prime} R^{-1} X & X^{\prime} R^{-1} Z \\
Z^{\prime} R^{-1} X & Z^{\prime} R^{-1} Z+G^{-1}
\end{array}\right] \cdot\left[\begin{array}{l}
\hat{\beta} \\
\tilde{\hat{u}} \\
\tilde{\sim}
\end{array}\right]=\left[\begin{array}{c}
X^{\prime} R^{-1} y \\
\underset{\sim}{Z} R^{-1} y \\
\sim
\end{array}\right]
$$

e sua solução leva aos resultados:

$$
\begin{gathered}
\hat{\sim}=\left(Z^{\prime} R^{-1} Z+G^{-1}\right)^{-1} Z^{\prime} R^{-1}{\left.\underset{\sim}{y}-X_{\sim}^{\hat{\beta}}\right)}_{\hat{\sim}_{\sim}^{\hat{\beta}}=\left\{X^{\prime}\left[R^{-1}-R^{-1} Z \cdot\left(Z^{\prime} R^{-1} Z+G^{-1}\right)^{-1} Z^{\prime} R^{-1}\right] X\right\}^{-} \cdot X^{\prime}\left[R^{-1}-R^{-1} Z\left(Z^{\prime} R^{-1} Z+G^{-1}\right)^{-1} Z^{\prime} R^{-1}\right]_{\sim}^{y}}
\end{gathered}
$$

Nas análises uni-característica e bi-características, foi considerado como efeito fixo (vetor $\underset{\sim}{\beta}$ ) a incubação, e como efeito aleatório (vetor $\underset{\sim}{u}$ ), o valor genético aditivo direto dos animais para todas as características avaliadas.

A tendência genética para todas as características foi determinada regredindo as médias anuais das predições do valor genético (VG) dos animais, obtidos através das análises uni-característica com o pacote DXMUX que integra o programa DFREML, em relação ao ano de nascimento do animal, segundo o modelo de regressão:

$$
y_{j}=a+b \cdot x_{j}+\varepsilon_{j}
$$

onde $y_{j}$ : é o valor genético médio dos animais nascidos no $\mathrm{j}$-ésimo ano; $\mathrm{x}_{\mathrm{j}}$ : é o j-ésimo ano de nascimento; $a$ : é a constante da equação; b: é o coeficiente angulação da equação (coeficiente de regressão linear); $\varepsilon_{\varphi} ;$ é o erro aleatório $\operatorname{com} \varepsilon \sim N\left(o ; \sigma_{Y}^{2}\right)$.

A análise de regressão foi realizada através do programa BioEstat 4, o que possibilitou verificar, por meio de regressão linear, as evoluções genéticas para todas as características estudadas.

\section{Resultados e Discussão}


VAYEGO, S.A., DIONELLO, N.J.L. e FIGUEIREDO, E.A.P. Estimativas de parâmetros genéticos e tendências genéticas para algumas características de importância econômica em linhagem materna de frango de corte sob seleção. PUBVET, Londrina, V. 5, N. 29, Ed. 176, Art. 1191, 2011.

As médias, desvios-padrão, coeficientes de variação, mínimos e máximos e o número de aves avaliadas em cada característica são apresentados na Tabela 1.

Tabela 1 - Número total de aves (n), Média ( $\bar{X}$ ); Desvio-Padrão (S); Coeficiente de Variação (CV); Menor valor observado (Min) e Maior valore observado (Max).

\begin{tabular}{lllllll}
\hline Característica & $\mathrm{n}$ & $\bar{X}$ & $\mathrm{~S}$ & $\mathrm{CV} \%$ & Min & Max \\
\hline P42 (g) & 1962 & 1799,09 & 120,52 & 6,70 & 1450 & 2150 \\
IMS (dias) & 1962 & 200,38 & 23,55 & 11,76 & 150 & 245 \\
PD35 (\%) & 1907 & 71,04 & 11,02 & 15,52 & 23,33 & 97,30 \\
PD64 (\%) & 1933 & 68,28 & 10,78 & 15,78 & 29,95 & 92,41
\end{tabular}

P42: peso vivo aos 42 dias de idade; IMS: idade à maturidade sexual; PD35: Produção de ovos às 35 semanas de idade; PD64: Produção de ovos às 64 semanas de idade.

O peso corporal médio aos 42 dias de idade foi de 1799,09 $\pm 120,52 \mathrm{~g}$, superior ao encontrado por Ledur et al. (1992) que variou entre $839,11 \mathrm{~g} \mathrm{e}$ $1151,04 \mathrm{~g}$, ao relatado por MALLIK et al. (1997), 1057,92g. SCHMIDT et al. (1992) relatam peso médio aos 42 dias de idade de $1345,8 \pm 415 \mathrm{~g}$, inferior ao encontrado nesse trabalho. Com relação a idade média à maturidade sexual SCHMIDT et al. (1992) relatam valores variando entre $148,75 \pm 9,93$ dias e $151,7 \pm 10,42$ dias e BHARAT \& SING (1998) encontraram idade média de 190,55 dias, valores inferior ao encontrado nesse trabalho, média de 200,38 \pm 23,55 dias. A produção média de ovos observada foi de $71,04 \pm 11,02 \%$ e $68,28 \pm 10,78 \%$, respectivamente, para produção ás 35 e 64 semanas de idade. Esses valores foram superiores aos relatados por LEDUR et al. (1994), que variaram entre $56,29 \pm 0,49 \%$ e $59,06 \pm 0,62 \%$ para produção de ovos até as 40 semanas de idade de duas linhagens de matrizes. Os coeficientes de variação encontrados para as características IMS (dias), PD35 (\%) e PD64 (\%) foram moderadamente altos, variando de $11,76 \%$ a $15,78 \%$. Isso indica alta 
VAYEGO, S.A., DIONELLO, N.J.L. e FIGUEIREDO, E.A.P. Estimativas de parâmetros genéticos e tendências genéticas para algumas características de importância econômica em linhagem materna de frango de corte sob seleção. PUBVET, Londrina, V. 5, N. 29, Ed. 176, Art. 1191, 2011.

variabilidade fenotípica para as características avaliadas, o que pode resultar também em variabilidade genética.

As estimativas dos componentes de (co)variâncias e herdabilidades para as características estudadas são apresentadas na Tabela 2.

Tabela 2 - Estimativas das variâncias genéticas aditivas diretas $\left(\sigma_{A}^{2}\right)$, variâncias fenotípicas $\left(\sigma_{P}^{2}\right)$, variâncias residuais $\left(\sigma_{E}^{2}\right)$ e herdabilidades $\left(\mathrm{h}^{2}\right)$ e erro padrão (EP)

\begin{tabular}{lcccc}
\hline Características & P42 & IMS & PD35 & PD64 \\
\hline$\sigma_{A}^{2}$ & 3888,10 & 24,50 & 28,91 & 28,63 \\
$\sigma_{E}^{2}$ & 6546,00 & 90,27 & 92,55 & 88,76 \\
$\sigma_{P}^{2}$ & 10434,00 & 114,77 & 121,47 & 117,38 \\
& \multicolumn{4}{c}{ Componentes de (co)variâncias } \\
$\mathrm{h}^{2}$ & 0,37 & 0,21 & 0,24 & 0,24 \\
EP & 0,05 & 0,04 & 0,05 & 0,04
\end{tabular}

P42: peso vivo aos 42 dias de idade; IMS: idade de maturidade sexual; PD35: Produção de ovos às 35 semanas de idade; PD64: Produção de ovos às 64 semanas de idade.

A herdabilidade para peso aos 42 dias de idade, 0,37 com erro padrão de 0,05, está dentro dos limites relatado por LEDUR et al. (1992 e 1994), 0,27 a 0,56 e 0,26 a 0,44, em duas linhagens através de diferentes metodologias, CARDELLINO \& ROVIRA (1987), 0,30 a 0,50 e SINGH \& TREHAN (1994), 0,30 a 0,52. Semelhante aos valores apresentados por AZEVEDO JR. et al. (2002), 0,33, MALLIK et al. (1997), 0,38, superior aos intervalos relatados por SCHMIDT et al. (1992), 0,30 a 0,32 e MALLIK et al. (2003), 0,13 a 0,23, superior ao valor citado por ARGENTÃO et al. (2002), 0,33 e SINGH et al. (1998), 0,11 e inferior ao valor relatado por RANCE et al. (2002), 0,52. É um valor moderadamente alto, o que significa que a característica P42 pode fornecer uma resposta eficiente à seleção fenotípica. A herdabilidade para 
VAYEGO, S.A., DIONELLO, N.J.L. e FIGUEIREDO, E.A.P. Estimativas de parâmetros genéticos e tendências genéticas para algumas características de importância econômica em linhagem materna de frango de corte sob seleção. PUBVET, Londrina, V. 5, N. 29, Ed. 176, Art. 1191, 2011.

idade à maturidade sexual foi moderada, 0,21 com erro padrão de 0,04, semelhante às relatadas por SINGH et al. (1999 e 2001), 0,25 e 0,18, dentro da variação apresentada por CARDELLINO \& ROVIRA (1987), 0,20 a 0,40, e DANBARO et al. (1995), 0,18 a 0,63 e inferiores às descritas por CUSTÓDIO (1997), 0,36, SCHMIDT et al. (1997), 0,31 e SINGH et al. (2000), 0,44.

As herdabilidades para produção de ovos foram moderadas, $0,24 \mathrm{com}$ erro padrão de 0,05 e 0,24 com erro padrão de 0,04, acumulada às 35 e 64 semanas de idade respectivamente), sendo semelhantes às apresentadas por SINGH et al. (1999), 0,25, superiores às relatadas por SCHMIDT et al. (1997), 0,17 , e SINGH et al. (2000), 0,16. Entretanto, foram inferiores ás descritas por LEDUR et al. (1994) para duas linhagens, 0,30 e 0,31 e por LOPES \& QUAAS (1997), 0,34. Apesar de serem moderadas, as herdabilidades observadas para produção de ovos indicam que se podem obter ganhos genéticos significativos na seleção por essa característica.

As estimativas de correlações fenotípica, genética e ambiental entre as características estudadas, são apresentadas na Tabela 3.

Tabela 3 - Estimativas de correlações fenotípica $\left(r_{P}\right)$, genética aditiva direta $\left(r_{\mathrm{A}}\right)$ e ambiental $\left(r_{\mathrm{E}}\right)$ entre as características analisadas.

\begin{tabular}{lccc}
\hline & $r_{A}$ & $r_{E}$ & $r_{P}$ \\
\hline P42 x IMS & 0,24 & 0,06 & 0,11 \\
P42 x PD35 & $-0,23$ & $-0,01$ & $-0,08$ \\
P42x PD64 & $-0,28$ & $-0,03$ & $-0,11$ \\
IMS x PD35 & $-0,42$ & $-0,23$ & $-0,28$ \\
IMS x PD64 & $-0,16$ & $-0,01$ & $-0,04$ \\
PD35 x PD64 & 0,47 & 0,46 & 0,47 \\
\hline
\end{tabular}

P42: peso vivo aos 42 dias de idade; IMS: idade à maturidade sexual; PD35: Produção de ovos às 35 semanas de idade; PD64: Produção de ovos às 64 semanas de idade.. 
VAYEGO, S.A., DIONELLO, N.J.L. e FIGUEIREDO, E.A.P. Estimativas de parâmetros genéticos e tendências genéticas para algumas características de importância econômica em linhagem materna de frango de corte sob seleção. PUBVET, Londrina, V. 5, N. 29, Ed. 176, Art. 1191, 2011.

De acordo com CARDELLINO \& ROVIRA (1987), o grau de correlação genética entre duas características é importante para controlar diretamente a mudança genética da característica quando se seleciona através de outra.

A correlação genética entre, peso aos 42 dias e idade à maturidade sexual $(0,24)$ indica uma relação positiva e moderada entre as características, pois, quanto maior o peso aos 42 dias mais elevada a idade à maturidade sexual. As correlações genéticas entre peso aos 42 dias e produção de ovos $(-0,23$ e 0,28), respectivamente para PD35 e PD64, foram semelhantes ao valor relatado por LEDUR et al. (1994), -0,26 e indicam que quanto maior o peso aos 42 dias de idade, menor a produção de ovos. Desse modo, a seleção por maior peso aos 42 dias de idade pode influenciar a idade à maturidade sexual e à produção de ovos. Aves com maior peso corporal aos 42 dias de idade atingem a maturidade sexual mais tarde e apresentam produção de ovos reduzida.

A tendência genética para a característica peso aos 42 dias de idade (Figura 1) foi significativa $(p<0,05)$ e crescente $(+2,07 \mathrm{~g} / \mathrm{ano})$, indicando que, ao longo das gerações, o peso aos 42 dias de idade das aves da linhagem estudada tende a aumentar.

A tendência genética para a característica idade à maturidade sexual (Figura 2) foi crescente $(+0,06 \mathrm{dia} / \mathrm{ano})$, porem não significativa $(p>0,05)$. Através da observação gráfica, parece que houve um equilíbrio ao longo do trabalho de seleção, o que pode representar a estabilidade da idade à maturidade sexual das aves da linhagem estudada.

As tendências genéticas para as características de produção de ovos (Figuras 3 e 4$)$ foram significativas $(p<0,05)$ e crescentes $(+0,18 \%$ e $+0,27 \%$, para PD35 e PD64, respectivamente), indicando que, ao longo do trabalho de seleção, a produção de ovos das aves da linhagem estudada tende a aumentar. 
VAYEGO, S.A., DIONELLO, N.J.L. e FIGUEIREDO, E.A.P. Estimativas de parâmetros genéticos e tendências genéticas para algumas características de importância econômica em linhagem materna de frango de corte sob seleção. PUBVET, Londrina, V. 5, N. 29, Ed. 176, Art. 1191, 2011.

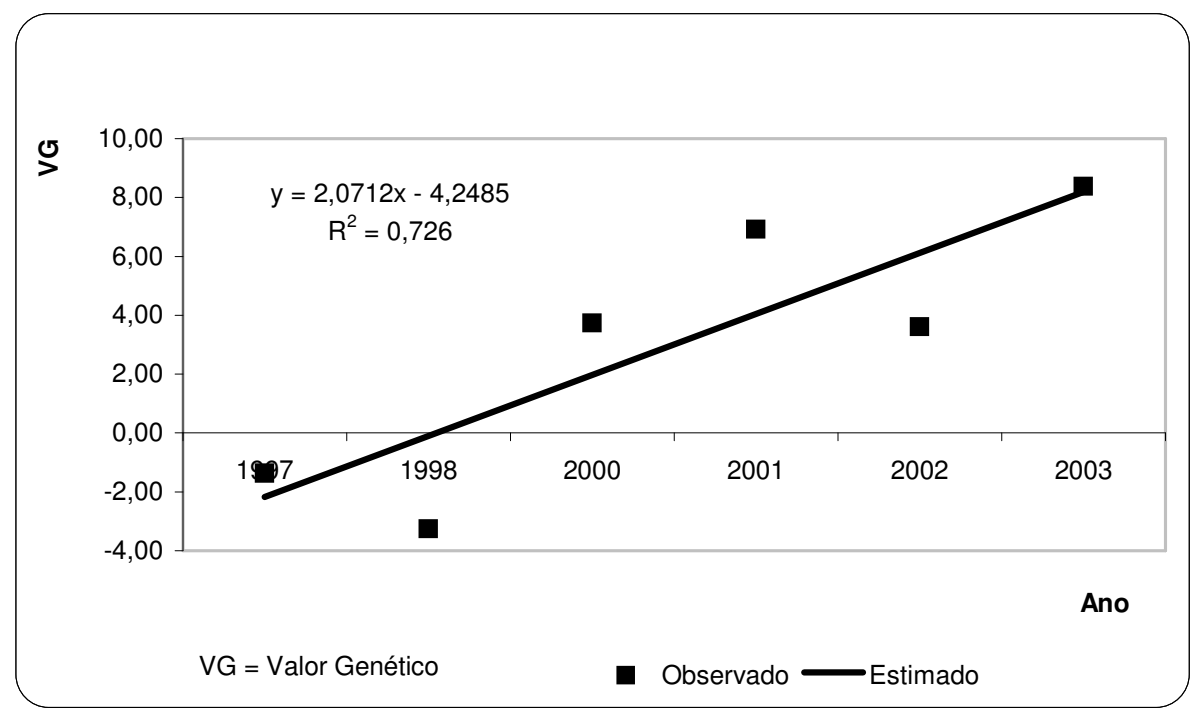

Figura 1 - Tendência genética para peso aos 42 dias de idade $(\mathrm{g})$

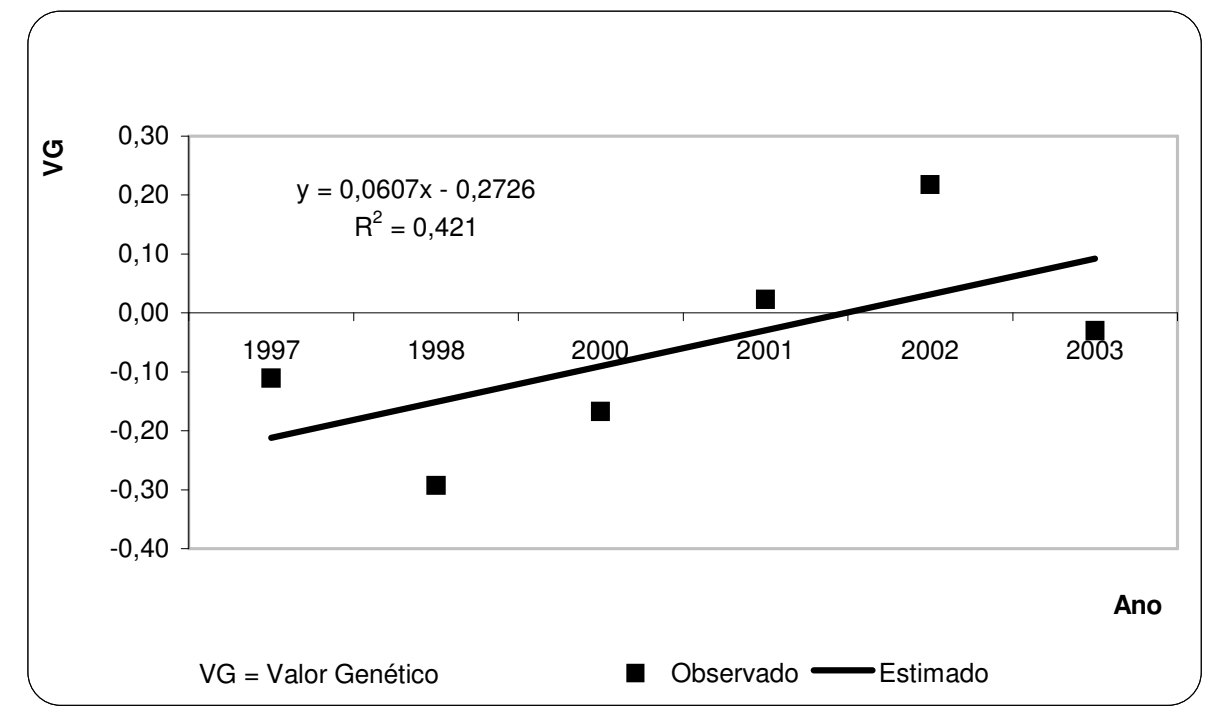

Figura 2 - Tendência genética para idade à maturidade sexual (dias) 
VAYEGO, S.A., DIONELLO, N.J.L. e FIGUEIREDO, E.A.P. Estimativas de parâmetros genéticos e tendências genéticas para algumas características de importância econômica em linhagem materna de frango de corte sob seleção. PUBVET, Londrina, V. 5, N. 29, Ed. 176, Art. 1191, 2011.

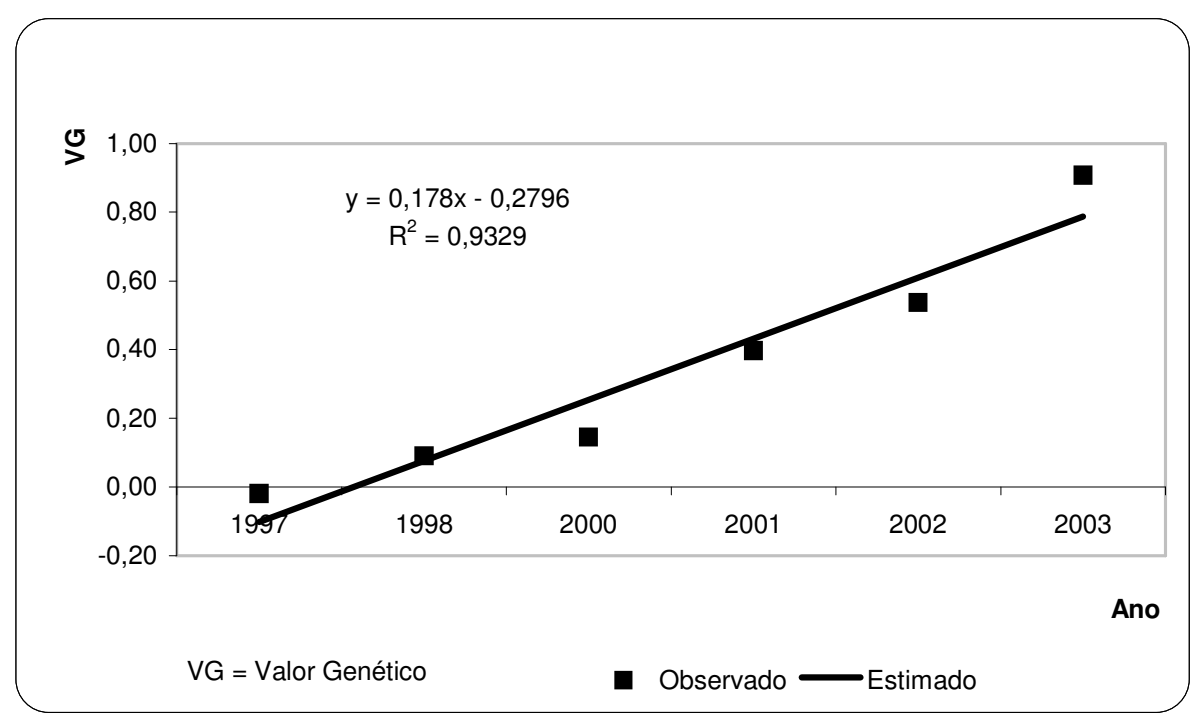

Figura 3 - Tendência genética para produção de ovos até a $35^{a}$ semana de idade $(\%)$

CHUNG et al. (1999) descrevem uma tendência genética para idade à maturidade sexual de $-2,59$ dias, de 11,9 ovos para produção de ovos até a $43^{\mathrm{a}}$ semana de idade e de 5,70 ovos para produção de ovos da $44^{\mathrm{a}}$ a $57^{\mathrm{a}}$ semana de idade. ZEIBA et al. (2003) também relatam tendência genética para idade à maturidade sexual de $-0,62$ dia, para produção de ovos nas primeiras 15 semanas de 0,69 ovo e para produção de ovos durante as 44 semanas de idade de 2,64, evidenciando os progressos alcançados ao longo do trabalho de seleção para essas características. 
VAYEGO, S.A., DIONELLO, N.J.L. e FIGUEIREDO, E.A.P. Estimativas de parâmetros genéticos e tendências genéticas para algumas características de importância econômica em linhagem materna de frango de corte sob seleção. PUBVET, Londrina, V. 5, N. 29, Ed. 176, Art. 1191, 2011.

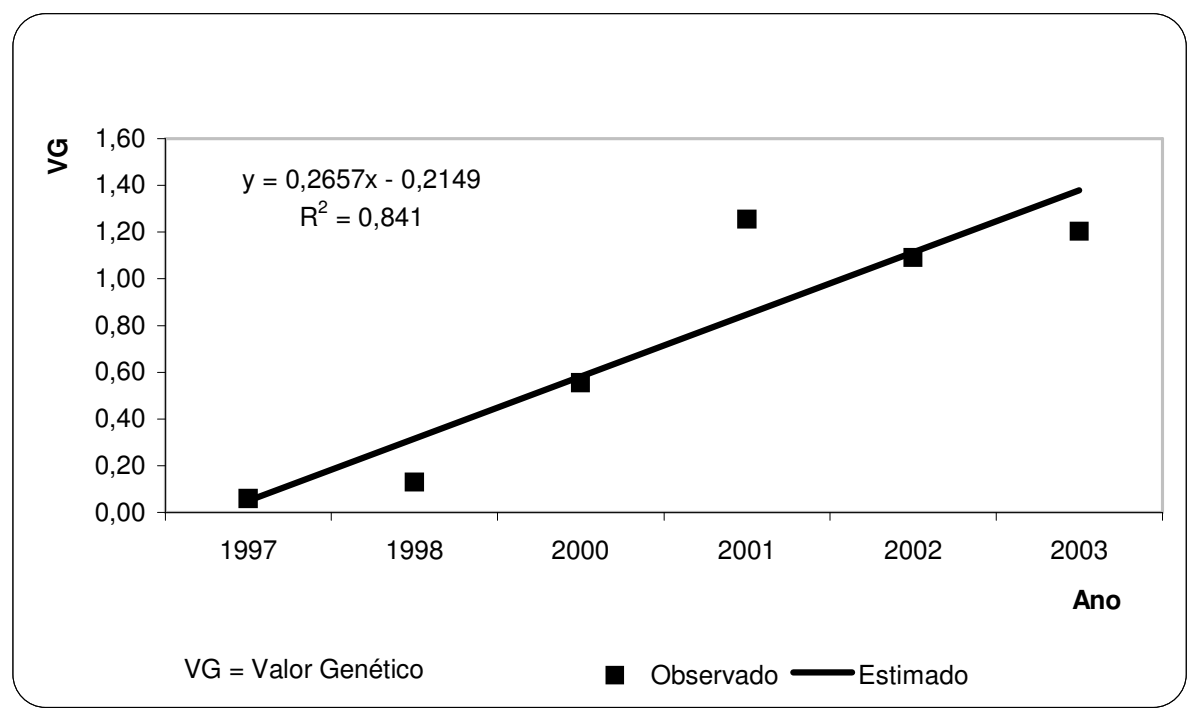

Figura 4 - Tendência genética para produção de ovos até a $64^{\mathrm{a}}$ semana de idade $(\%)$

\section{Conclusões}

As estimativas de herdabilidade para as características estudadas foram de moderadas, indicando que uma parcela relativamente grande da variação observada nas características é decorrente de diferenças nos genes de efeito aditivo e que é possível alcançar ganhos genéticos, por meio de seleção, nas aves da linhagem estudada.

O uso da característica peso corporal aos 42 dias de idade como critério de seleção é capaz de exercer grande influência sobre as demais características estudadas, elevando a idade à maturidade sexual e reduzindo produção de ovos, o que geralmente não é o desejado em uma linhagem fêmea.

A seleção através da idade à maturidade sexual resulta num impacto favorável à produção de ovos, indicando que, quanto menor a idade à maturidade sexual, maior será a produção de ovos, como era esperado. Contudo, em se tratando de linhagem de corte, não se deve, simplesmente, descartar a seleção para maior peso corporal aos 42 dias de idade, e sim 
VAYEGO, S.A., DIONELLO, N.J.L. e FIGUEIREDO, E.A.P. Estimativas de parâmetros genéticos e tendências genéticas para algumas características de importância econômica em linhagem materna de frango de corte sob seleção. PUBVET, Londrina, V. 5, N. 29, Ed. 176, Art. 1191, 2011.

aplicar pesos adequados em cada característica de interesse de modo que se obtenha ganhos genéticos significativos.

Um progresso genético significativo está sendo obtido ao longo da seleção para as características peso corporal aos 42 dias de idade e produção de ovos.

\section{Literatura Citada}

ARGENTÃO, C. et al. Genetic and phenotypic parameters of growth and carcass traits of male line of broilers raised in tropical conditions. In. CONGRESS ON GENETICS APLLIED TO LIVESTOCK PRODUCTION, 7., 2002, Montpellier. Proceedings...Castanet - Tolosan. Organising comitee WCGALP, 2002.v. 30. p. 333-336.

AZEVEDO, P.C. et al. Comparação de metodologias para estimação de parâmetros genéticos em população de aves submetida a seleção. Arquivo Brasileiro de Medicina Veterinaria e Zootecnia, v. 54, p. 518-524, 2002.

BHARAT, B.; SINGH, R.V. Genetic studies on growth, feed conversion, reproduction and production traits in a broiler dam line. Indian Journal of Animal Science, v. 68, p. 1202-1204, 1998.

CARDELLINO, R.A.; ROVIRA,J. Mejoramento genético animal. Montevideo. Hemisfério Sur, 1987. 253p.

CARNEIRO Jr., J.M. et al., Avaliação de Métodos de Estimação de Componentes de Variância Utilizando Dados Simulados. Revista Brasileira de Zootecnia, v 33, n 2, p. 328 - 336, 2004.

CHUNG, K.H.; SEO, K.S.; LEE, S.C. et al. Estimation of genetic trend on economic traits in a line of White Leghorn layers. Korean Journal of Animal Science, v. 41, p. 271-276, 1999.

CUSTÓDIO, R.W.S. Obtenção de parâmetros genéticos com substituição de galos em galinhas para ovos. Revista Brasileira de Zootecnia, v. 24, p. 697-703, 1997.

DANBARO, G.; OYAMA, K.; MUKAI, F. et al. Heritabilities and genetic correlation from a selection experiment in broiler breeders using restricted maximum likelihood. Japanese Poultry Science, v. 32, p. 257-266, 1995.

FIGUEIREDO, E.A.P. A evolução da genética avícola e suinicola no mundo. Concórdia, 2005. Disponível em: <http://www.cnpsa.embrapa.br/?ids=Sq4r54z6x\&ano=2005 > Acesso em: 28/03/07.

HENDERSON, C.R. Aplications of linear models in animal breeding. Guelph: University of Guelph, 1984. 462p.

KENNEDY, B.W. Bias and mean square error fron ignoring genetic groups in mixed model sire evaluation. Journal Dairy Science, v. 64, p.689-697, 1981.

LEDUR, M.C. et al. Parâmetros genéticos e fenotípicos para peso corporal em diferentes idades em linhagens de frango de corte. Revista Brasileira de Zootecnia, v. 21, p. 667-673, 1992.

LEDUR, M.C. et al. Parâmetros genéticos e fenotípicos em linhagens de aves selecionadas para corte. Pesquisa Agropecuária Brasileira, v. 29, p. 503-508, 1994.

LOPES, P.S.; QUAAS, R.L. Estimação de parâmetros genéticos em aves de corte. Revista Brasileira de Zootecnia, v. 26, p. 1119-1123, 1997. 
MALLIK, B.N.; MISHRA, P.K.; MISHRA, S.C. Inheritance of 6-week body weight, breast angle, shank length and keel length in broiler chickens. Indian Journal of Poultry Science, $v$. 32, p. 249-252, 1997.

MALLIK, B.K. et al. Evaluation of genetic parameters in a synthetic broiler chicken flock due to selection for high six week body weight. Indian Journal of Poultry Science, v. 38, p. 225-229, 2003.

MARTINS, E.N. Perspectivas do melhoramento genético de codornas no Brasil. In. SIMPÓSIO INTERNACIONAL DE COTURNICULTURA, 1., 2002, Lavras. Anais... Lavras. UFLA, 2002. p. $109-112$.

MEYER, K. DFREML - A set programs to estimate variance components under an individual animal model. Journal Dairy Science, v 71, supll. 2, p. 33-34, 1988.

MEYER, K.; THOMPSON, R. Bias in variance and covariance components estimators due to selection on a correlated trait. Journal Animal Breeding Genetic, v 71, p. 773-779, 1984.

PEREIRA, J.C.C. Melhoramento genético Aplicado à produção Animal. Ed. UFMG, Belo Horizonte - MG, 1996, 416p.

RANCE, K.A.; McENTEE, G.M.; McDEVITT, R.M. Genetic and phenotypic relatiobships between and within support and demand tissues in a single line of broiler chicken. British Poultry Science, v. 43, p. 518-527, 2002.

RESENDE, M.D.V.; ROSA-PEREZ, J.R.H. Genética e Melhoramento de Ovinos. Curitiba. Ed. UFPR, 2001. $185 \mathrm{p}$.

SCHMIDT, G.S. et al. Herdabilidade do peso aos 42 dias de linhagens de aves para corte. Revista Brasileira de Zootecnia, v. 21, p. 772-778, 1992.

SCHMIDT, G.S. et al. Efeito da seleção para características produtivas sobre o intervalo de oviposição em linhagens de aves para postura. Revista Brasileira de Zootecnia, v. 22, p. 289-293, 1997

SINGH, S. et al. Estimation of genetic and phenotypic parameters of economic traits of White Leghorn. Indian Journal of Poultry Science, v. 36, p. 163-168, 2001.

SINGH, U.B. et al. Evaluation of genetic parameters in a selected synthetic sire of broilers. Indian Journal of Poultry Science, v. 34, p. 25-28, 1999.

SINGH, B. et al. Genetic parameters of growth, egg production and egg quality traits in White Leghorn. Indian Journal of Poultry Science, v. 35, p. 13-16, 2000.

SINGH, S. et al. Inheritance of growth and conformation traits in broiler chickens. Indian Journal of Poultry Science, v. 33, p. 74-76, 1998.

SINGH, R.; TREHAN, P.K. Genetic and phenotypic parameters of body and muscle weights and abdominal fat in meat-type chicken. Indian Journal of Animal Science, v. 64, p. 388392, 1994.

ZIEBA, G. et al. Genetic trends of laying in maternal (M55) and paternal (V44) strains of hens. Animal Science Papers and Reports, v. 21, p. 241-249, 2003. 